\title{
Sleep disorders and gout in Australian adults
}

\author{
Julia New-Tolley ${ }^{1} \mathbb{D}$, Amy C. Reynolds² ${ }^{2}$, Sarah L. Appleton² ${ }^{\mathbb{D}}$, Tiffany K. Gill ${ }^{3} \mathbb{D}$, Susan Lester ${ }^{1}$, \\ Robert J. Adams ${ }^{2}$ (D) and Catherine L. Hill ${ }^{1 *}$ (D)
}

\begin{abstract}
Background: The aims of our study were two-fold. Firstly, to determine if there is an association between gout and OSA in a representative Australian adult population. Secondly, to explore associations between gout and patient reported sleep outcomes.

Methods: A cross-sectional national online survey of a representative sample of Australian adults $\geq 18$ years assessed self-reported doctor-diagnosed OSA, insomnia and patient reported sleep outcomes. Possible undiagnosed OSA was estimated using self-reported frequent loud snoring and witnessed apnoeas. Participants self-reported physician-diagnosed gout and other health conditions. Multivariable logistic regression analyses were performed for both objectives. Odds ratios with 95\% confidence intervals were reported.

Results: There were 1948 participants of whom 126 (6.5\%) had gout and 124 (6.4\%) had diagnosed sleep apnoea. After adjusting for age, body mass index (BMI), sex, alcohol intake and the presence of arthritis, those with obstructive sleep apnoea diagnosed on polysomnography were twice as likely to report having gout compared to those without. ( $\mathrm{OR}=2.6,95 \% \mathrm{Cl} 1.5-4.6)$. Additionally, participants with symptoms suggestive of sleep apnoea were also twice as likely to have gout compared to those without $(\mathrm{OR}=2.8,95 \% \mathrm{Cl} 1.6-5.1)$. There was also a higher likelihood of restless legs syndrome, insomnia and worry about sleep in patients with gout.

Conclusion: Diagnosed and suspected OSA are associated with higher likelihood of gout. Participants with gout are also more likely to report suffering from restless legs syndrome, insomnia and worry about their sleep. Given the morbidity associated with sleep problems, we should be vigilant regarding sleep health in our patients with gout.
\end{abstract}

Keywords: Gout, Sleep Apnoea, obstructive, Sleep hygiene, Sleep disorders

\section{Introduction}

Gout is the most prevalent inflammatory arthropathy with a prevalence of $6.8 \%$ in South Australia, and it is the most common form of inflammatory arthritis in men [1]. Gout is associated with co-morbidities including the metabolic syndrome and cardiovascular disease [2]. Obstructive sleep apnoea (OSA), which is also

\footnotetext{
* Correspondence: Catherine.Hill@sa.gov.au

${ }^{1}$ Rheumatology Unit, The Queen Elizabeth Hospital, Woodville, SA, Australia Full list of author information is available at the end of the article
}

associated with cardiovascular morbidity, is also very common, with a self-reported prevalence of $8 \%$ in the Australian population [3]. A higher prevalence of incident OSA has been observed in older adults with gout [4]. A recent meta-analysis has shown an association between gout, serum uric acid and OSA [5]. Overall, it found that serum uric acid levels in patients with OSA were higher than in controls. In addition, individuals with OSA had a higher risk of developing gout, although this was not statistically significant (HR 1.25 95\% 0.9 1.7).

(c) The Author(s). 2021 Open Access This article is licensed under a Creative Commons Attribution 4.0 International License, which permits use, sharing, adaptation, distribution and reproduction in any medium or format, as long as you give appropriate credit to the original author(s) and the source, provide a link to the Creative Commons licence, and indicate if changes were made. The images or other third party material in this article are included in the article's Creative Commons licence, unless indicated otherwise in a credit line to the material. If material is not included in the article's Creative Commons licence and your intended use is not permitted by statutory regulation or exceeds the permitted use, you will need to obtain permission directly from the copyright holder. To view a copy of this licence, visit http://creativecommons.org/licenses/by/4.0/ The Creative Commons Public Domain Dedication waiver (http://creativecommons.org/publicdomain/zero/1.0/) applies to the data made available in this article, unless otherwise stated in a credit line to the data. 
The association between OSA and gout may be explained by intermittent airway obstruction during sleep leading to hypoxia, and resulting in increased serum uric acid via alteration in cellular metabolism [6]. Given the cardiovascular complications of both conditions, and treatability once diagnosed, this is an important area for further research.

There is likely to be a bidirectional relationship between sleep and gout, as gout flares may be influenced by circadian rhythms, and sleep quality is likely to be influenced by gout flares [7]. A study of 724 individuals with gout highlighted that attacks are twice as likely to occur at night [8]. We hypothesized that gout is therefore also likely to be associated with sleep disruption, which is known to lead to significant sequelae such as reduced work performance and road safety [3].

The aims of our study were two-fold. Firstly, to determine if there is an association between OSA and gout in a representative Australian adult population. Secondly, to explore associations between gout and patient reported sleep outcomes.

\section{Materials and methods}

The aims of these study were addressed with a secondary analysis of the existing database of the Sleep Health Foundation 2019 web-based sleep health survey. The primary aim of this cross-sectional survey was to investigate prevalence of sleep disorders and sleep problems in the Australian population. The survey additionally included self-reported diagnoses of diverse chronic health conditions, including gout. Characteristics of the sample surveyed have been reported elsewhere [9]. Briefly, the sample incorporated Australian adults $(\geq 18$ years, $n=$ 2044) recruited from an online survey panel by Dynata. The online panel comprises $>500,000$ Australians, and allows for recruitment of a representative sample of Australian adults using a three-step randomisation process aimed at reducing recruitment bias [3, 9]. Participants were naïve to the content and aims of the survey during initial recruitment and screening to reduce bias. The CHERRIES checklist has previously been reported for this study, see Appleton et al. for details [9].

\section{Obstructive sleep apnoea (OSA)}

Diagnosed OSA was determined by an affirmative response to the question 'Have you ever been told by a doctor that you have any of the following conditions? Obstructive Sleep Apnoea' (response items: yes, no, refused, don't know). Possible undiagnosed OSA (henceforth possible OSA) was determined based on the frequency in the past month of symptoms including observed frequent/loud snoring, and observed pauses in breathing/ stopping breathing during sleep. Possible OSA was categorised as self-report of witnessed breathing pauses (i.e apnoeas).

Doctor diagnosed medical conditions were determined with the question 'Have you ever been told by a doctor that you have any of the following conditions?...' for gout, arthritis, high blood pressure, obesity, and heart disease. Response options were yes, no, refused or don't know; participants were included in analyses if they provided either a yes or no response to the question on gout.

\section{Patient reported outcome measures for sleep}

Patient reported outcome measures for sleep were assessed with the following questions and answer options included in Table 1.

\section{Covariates}

Age (years), sex (categories: male, female and other) and Body Mass Index from self-reported height and weight were included as covariates. Standard alcoholic drinks were self-reported, using the question: "Thinking about alcoholic beverages such as beer, wine, liquor or mixed drinks, how many alcoholic beverages do you typically drink each week?". Responses were categorised to allow comparison to the Australian guidelines to reduce health risks from drinking alcohol [10] as 'none', ' $\leq 1$ standard drink/day', '>1 to $\leq 2$ standard drinks/day', and ' $>2$ standard drinks/day'.

\section{Data analysis}

Data were analysed using IBM SPSS version 26.0 (IBM Corporation). Significant differences in sociodemographic and health characteristics of respondents by gout (yes or no) were examined using Mantel-Haenszel test of trend or Pearson $\chi^{2}$ statistic. Multivariable logistic regression analysis was used to examine associations between OSA (predictor) and gout (outcome) for Objective 1, adjusting for known correlates of gout (age, sex, BMI, alcohol consumption and arthritis).

Multivariable logistic regression analyses were used to examine associations between gout (predictor) and each of the patient reported sleep outcomes (summarised in Fig. 1), with each model adjusted for age, sex and BMI, selected based on established relationships with sleep problems in community samples [3, 9]. Significance values for all models reported are based on the Wald statistic.

\section{Results}

Of the 2044 respondents to the 2019 Sleep Health Foundation survey, 1948 (95.3\%) provided a yes/no response when asked about gout. Respondents who indicated a diagnosis of gout $(n=126,6.5 \%)$ were more likely to be male than female $(11.2 \% \mathrm{v} 2.0 \%, p<0.001)$, and reported a higher prevalence of comorbidities including heart 
Table 1 Patient reported outcomes for sleep

\begin{tabular}{|c|c|c|}
\hline Outcome & Original question & $\begin{array}{l}\text { Answer options. } \\
\text { (Answers which coded for } \\
\text { outcome are in italics) }\end{array}$ \\
\hline $\begin{array}{l}\text { Doctor diagnosed restless legs syndrome (RLS) or } \\
\text { periodic leg movements during sleep (PLMS) }\end{array}$ & Have you been diagnosed with restless legs or periodic leg movements of sleep & $\begin{array}{l}\text { 1. Yes } \\
\text { 2. No }\end{array}$ \\
\hline $\begin{array}{l}\text { Worried about getting to or maintaining sleep over } 3 \\
\text { nights/week }\end{array}$ & $\begin{array}{l}\text { 'How often have each of the following things disturbed your sleep or kept you } \\
\text { up at night in the past month? } \\
\text { - Worry about getting to sleep or getting back to sleep after waking during the } \\
\text { night'. }\end{array}$ & $\begin{array}{l}\text { 1. rarely or never } \\
\text { 2. a few nights a month } \\
\text { 3. a few nights a week } \\
\text { 4. every or almost every night }\end{array}$ \\
\hline Discussing sleep with a health professional & $\begin{array}{l}\text { During the last } 12 \text { months have you discussed your sleep with any of the } \\
\text { following health professionals?' }\end{array}$ & $\begin{array}{l}\text { (Multiple response) } \\
\text { 1. general practitioner } \\
\text { 2. physiotherapist } \\
\text { 3. chiropractor } \\
\text { 4. specialist in private practice } \\
\text { 5. hospital physician (with or } \\
\text { without admission) } \\
\text { 6. other physician } \\
\text { 7. psychologist } \\
\text { 8. psychiatrist } \\
\text { 9. pharmacist } \\
\text { 10. other (specify) } \\
\text { Coded as" yes" if any one health } \\
\text { professional indicated }\end{array}$ \\
\hline \multirow[t]{2}{*}{ Pain which disturbs sleep } & 'How often does pain stop you from going to sleep at night?' & $\begin{array}{l}\text { 1. Never } \\
\text { 2. A few nights a week (1-3 } \\
\text { nights/week) } \\
\text { 3. Most nights ( } 4-6 \text { nights/week) } \\
\text { 4. Every night } \\
\text { 5. Don't know }\end{array}$ \\
\hline & How often does pain wake you up at night?' & $\begin{array}{l}\text { 1. Never } \\
\text { 2. A few nights a week (1-3 } \\
\text { nights/week) } \\
\text { 3. Most nights (4-6 nights/week) } \\
\text { 4. Every night } \\
\text { 5. Don't know }\end{array}$ \\
\hline Adequate sleep & $\begin{array}{l}\text { In the past month, how often have you experienced feeling you got } \\
\text { adequate or satisfactory sleep'? }\end{array}$ & $\begin{array}{l}\text { 1. rarely or never, } \\
\text { 2. a few nights a month, } \\
\text { 3. a few nights a week, } \\
\text { 4. every/almost every night' }\end{array}$ \\
\hline $\begin{array}{l}\text { Inadequate opportunity to sleep as a consequence of } \\
\text { their typical routine }\end{array}$ & $\begin{array}{l}\text { Does your current work schedule or typical weekday routine, including your } \\
\text { duties at home, allow you to get enough sleep? }\end{array}$ & $\begin{array}{l}\text { 1. All/most of the time } \\
\text { 2. Sometimes } \\
\text { 3. Rarely/never } \\
\text { 4. Don't know } \\
\text { 5. Refused }\end{array}$ \\
\hline
\end{tabular}

disease, arthritis, diabetes, high blood pressure and obesity than those without gout (see Table 2). Respondents with a diagnosis of gout were, on average, older than those who did not report a diagnosis of gout $(\mathrm{M}( \pm \mathrm{t} \mathrm{SD})$; $58.9( \pm 16.6)$ years and $(46.1 \pm 17.0)$ years respectively).

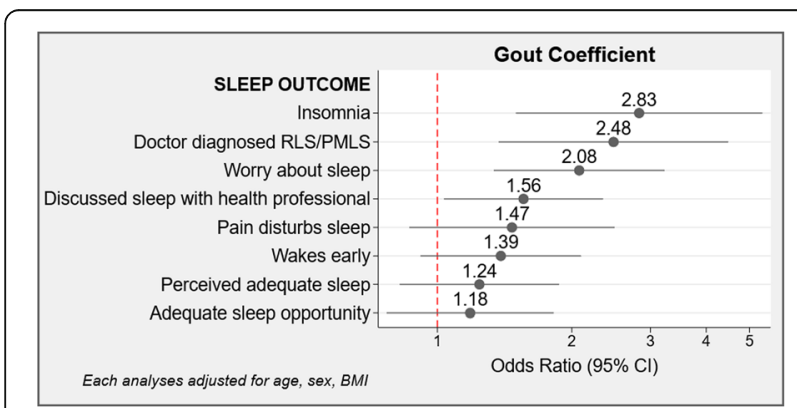

Fig. 1 Coefficient plot reflecting odds of patient reported sleep problems by doctor-diagnosed gout from multivariable adjusted models

\section{OSA and gout}

The likelihood of reporting gout when a respondent also had OSA (no OSA, symptoms of OSA or diagnosed OSA with PSG) is reported in Table 2. Respondents who had OSA symptoms or diagnosed OSA were 2.6 and 2.8 times more likely respectively to report gout than those who did not have OSA. The model containing all variableswas statistically significant $\chi^{2}(10, N=1692)=150.44$, $p<0.001$, explaining between $8.5 \%\left(\right.$ Cox \& Snell $\left.\mathbf{R}^{2}\right)$ and $22.1 \%$ (Nagelkerke $R^{2}$ ) of the variance in gout, and correctly classifying $93.4 \%$ of cases (see Table 3 ).

\section{Gout and patient reported sleep problems}

The results of multivariate adjusted logistic regression analyses for each sleep problem are presented in Fig. 1. Respondents with gout were 2.5 times more likely to report doctor diagnosed RLS/PLMS, were 2 times more likely to worry about their sleep, and were 1.6 times more likely to have discussed their sleep with a health 
Table 2 Sociodemographic characteristics, risk factors and comorbidity and by doctor-diagnosed gout

\begin{tabular}{|c|c|c|c|}
\hline & \multirow{2}{*}{$\begin{array}{l}\text { No Gout } \\
(n=1822) \\
n(\%)\end{array}$} & \multicolumn{2}{|l|}{$\begin{array}{l}\text { Gout } \\
(n=126)\end{array}$} \\
\hline & & $\bar{n}(\%)$ & $p^{a}$ \\
\hline \multicolumn{4}{|l|}{ Sociodemographics } \\
\hline Sex & & & $<0.001$ \\
\hline Female & $981(53.9)$ & $20(15.9)$ & \\
\hline Male & $839(46.1)$ & $106(84.1)$ & \\
\hline Age (years) & & & $<0.001$ \\
\hline $18-24$ & $207(11.4)$ & $5(4.0)$ & \\
\hline $25-34$ & $346(19.0)$ & $10(7.9)$ & \\
\hline $35-44$ & $366(20.1)$ & $11(8.7)$ & \\
\hline $45-54$ & $312(17.1)$ & $14(11.1)$ & \\
\hline $55+$ & $591(32.4)$ & $86(68.3)$ & \\
\hline Location & & & $<0.001$ \\
\hline Metro & $1284(70.5)$ & 70 (55.6) & \\
\hline Rural/Regional & $538(29.5)$ & $56(44.4)$ & \\
\hline Current domestic status & & & 0.87 \\
\hline Never/Divorced/Separated/Widow & $749(41.2)$ & $51(40.5)$ & \\
\hline Married/Partnered & $1069(58.8)$ & $75(59.5)$ & \\
\hline Income ${ }^{b}$ & & & 0.006 \\
\hline$\leq \$ 30,000$ & $316(19.8)$ & $31(25.6)$ & \\
\hline$\$ 30,001-\$ 50,000$ & $303(18.9)$ & $35(28.9)$ & \\
\hline$\$ 50,001-\$ 100,000$ & $571(35.7)$ & $34(28.1)$ & \\
\hline$\$ 100,001+$ & $410(25.6)$ & $21(17.4)$ & \\
\hline Financial strain & & & 0.10 \\
\hline Spend more than earn/get by & $689(39.8)$ & $59(47.2)$ & \\
\hline Save a bit/save a lot & $1043(60.2)$ & $66(52.8)$ & \\
\hline \multicolumn{4}{|l|}{ Risk factors } \\
\hline Body Mass Index (kg/m²) & & & $<0.001$ \\
\hline$<25$ & $663(41.8)$ & $25(22.1)$ & \\
\hline $25-29$ & $508(32.0)$ & $39(34.5)$ & \\
\hline$\geq 30$ & $417(26.3)$ & $49(43.4)$ & \\
\hline Alcohol consumption & & & $<0.001$ \\
\hline None & $653(35.8)$ & $28(22.2)$ & \\
\hline$\leq 1$ standard drink/day & $476(26.1)$ & $26(20.6)$ & \\
\hline $1-\leq 2$ standard drink/day & $110(6.0)$ & $14(11.1)$ & \\
\hline$>2$ standard drink/day & $583(32.0)$ & $58(46.0)$ & \\
\hline Smoking (current) & $409(22.7)$ & $30(23.8)$ & 0.77 \\
\hline \multicolumn{4}{|l|}{ Comorbidities } \\
\hline RLS/PLMS & $121(6.6)$ & $23(18.3)$ & $<0.001$ \\
\hline Heart Disease & $93(5.1)$ & $24(19.7)$ & $<0.001$ \\
\hline Arthritis & $332(18.3)$ & $50(41.0)$ & $<0.001$ \\
\hline Diabetes & $159(8.8)$ & 49 (39.8) & $<0.001$ \\
\hline High Blood Pressure & $409(22.5)$ & $82(65.6)$ & $<0.001$ \\
\hline Obesity & $417(26.3)$ & 49 (43.4) & \\
\hline
\end{tabular}


Table 2 Sociodemographic characteristics, risk factors and comorbidity and by doctor-diagnosed gout (Continued)

\begin{tabular}{lll}
\hline & $\begin{array}{l}\text { No Gout } \\
(\mathbf{n = 1 8 2 2}) \\
\mathbf{n}(\%)\end{array}$ & $\begin{array}{l}\text { Gout } \\
(\boldsymbol{n}=126)\end{array}$ \\
\hline $\begin{array}{l}\mathbf{n}(\%) \\
\boldsymbol{p}^{\boldsymbol{a}}\end{array}$ \\
Obstructive sleep apnoea (OSA) \\
No OSA & $1557(85.5)$ & $77(61.1)$ \\
OSA symptoms & $169(9.3)$ & $21(16.7)$ \\
OSA diagnosed with PSG & $96(5.3)$ & $28(22.2)$ \\
\hline
\end{tabular}

Abbreviations: RLS/PLMS Restless Legs Syndrome/Periodic Limb Movements in Sleep, PSG polysomnography

${ }^{a}$ significance values calculated from univariate $X^{2}$ analyses; ${ }^{b}$ columns which do not add up to totals indicate missing data in this variable

professional than those without gout. Over two thirds $(67.3 \%)$ of respondents with gout indicated that their routine allows sufficient sleep, and $62.8 \%$ felt that they regularly achieve adequate sleep. These findings were not significantly different to respondents without gout. In contrast, $15.0 \%$ of respondents with gout indicated they have doctor diagnosed RLS/PLMS compared to a prevalence of $6.7 \%$ in those without gout. Worry about sleep was also higher in respondents with gout (31.9\% compared with $23.6 \%$ ), and those with gout were more likely to have discussed sleep with a health professional than respondents without gout (38.9\% compared with $28.5 \%)$.

\section{Discussion}

In Australian adults, gout was more prevalent in those with diagnosed or probable sleep apnoea, after adjustment for relevant confounders. Of the 1948 participants, 126 (6.5\%) had gout, and 124 (6.4\%) had sleep apnoea diagnosed by polysomnography. A further 190 participants $(9.8 \%)$ had symptoms suggestive of sleep apnoea without a formal diagnosis. Even after accounting for age, BMI, sex, alcohol intake and the presence of arthritis, diagnosis of gout was 2.8 times more likely in respondents with possible OSA. A participant with diagnosed OSA was 2.6 times more likely to have gout. Our results are in keeping with two large primary care matched retrospective cohort studies, in which patients with sleep apnoea were almost twice as likely to have gout $[11,12]$. It is known than sleep apnea is under diagnosed in the community [13].

Our study was novel in that we found the association also emerged in those with suspected, but undiagnosed, sleep apnea. Our study design does not allow for consideration of the directionality of these relationships. However, a recent study by Singh and Cleveland showed a higher risk for OSA in patients with gout in the 5\% United States Medicare beneficiary sample. They

Table 3 Multivariable logistic regression predicting likelihood of reporting gout by obstructive sleep apnoea status

\begin{tabular}{|c|c|c|c|c|c|c|}
\hline & \multirow[t]{2}{*}{ Wald } & \multirow[t]{2}{*}{$d f$} & \multirow[t]{2}{*}{$p$} & \multirow{2}{*}{$\begin{array}{l}\text { Odds } \\
\text { Ratio }\end{array}$} & \multicolumn{2}{|c|}{ 95\% Confidence Interval } \\
\hline & & & & & $\mathrm{LLCl}$ & ULCI \\
\hline $\mathrm{OSA}^{a}$ & 18.93 & 2 & $<0.001$ & & & \\
\hline OSA Symptoms & 11.49 & 1 & 0.001 & 2.81 & 1.55 & 5.11 \\
\hline Diagnosed OSA & 10.65 & 1 & 0.001 & 2.61 & 1.47 & 4.64 \\
\hline Age (years) & 13.20 & 1 & $<0.001$ & 1.03 & 1.01 & 1.04 \\
\hline Sex $(\text { male })^{b}$ & 24.95 & 1 & $<0.001$ & 5.25 & 2.74 & 10.07 \\
\hline BMI $(\mathrm{kg} / \mathrm{m} 2)^{\mathrm{c}}$ & 4.91 & 2 & 0.09 & & & \\
\hline $25-29$ & 0.02 & 1 & 0.88 & 0.96 & 0.55 & 1.68 \\
\hline$\geqq 30$ & 2.53 & 1 & 0.11 & 1.57 & 0.90 & 2.72 \\
\hline Alcohol consumption $^{d}$ & 13.99 & 3 & 0.003 & & & \\
\hline$\leq 1$ per day & 0.07 & 1 & 0.79 & 0.92 & 0.50 & 1.70 \\
\hline 1-2 per day & 3.38 & 1 & 0.07 & 2.00 & 0.96 & 4.18 \\
\hline$>2$ per day & 7.57 & 1 & 0.006 & 2.13 & 1.24 & 3.66 \\
\hline Arthritis $^{\mathrm{e}}$ & 4.86 & 1 & 0.027 & 1.65 & 1.06 & 2.58 \\
\hline Constant & 148.60 & 1 & $<0.001$ & & & \\
\hline
\end{tabular}

${ }^{a}$ ref no OSA; ${ }^{b}$ ref, female; ${ }^{c}$ ref $\mathrm{BMI}<25 ;{ }^{\mathrm{d}}$ ref none; ${ }^{\mathrm{e}}$ ref no arthritis 
propose that two mechanisms are consistent between gout and OSA - specifically, inflammation and oxidative stress [4]. Prospective studies with gold-standard measurement of OSA, and inclusion of serum urate measures over time, will be required to further examine these relationships.

Our second aim was to explore the relationship between gout and patient reported sleep problems. Interestingly, participants with gout were twice as likely to have restless legs symptoms or periodic leg movements of sleep. Restless legs syndrome has been has reported associations with gout as well as many other comorbidities including obesity, diabetes, hypertension, thyroid disease and iron deficiency [14]. However, the mechanism behind the association between gout and restless legs syndrome is unclear. In fact, a 2019 study of 281 patients with restless legs syndrome showed reduced urate levels compared to controls matched by age and gender. It is worth noting however, that lower urate levels were also associated by increasing age, disease duration and haemoglobin level [15].

Given the prevalence of gout and the substantive financial burden of sleep-related conditions and flow on effects including productivity, employment, accidents and well-being, our findings highlight the importance of identifying and managing sleep problems in patients with gout [16]. Those with gout were also twice as likely to worry about sleep and 1.5 times as likely to have discussed sleep with a health professional. However, in those with gout, while there were trends towards issues with perceived adequacy of sleep and disruption of sleep secondary to pain, these effects were not significant. This result was surprising and not in keeping with our proposed hypothesis.

While gout is implicated in sleep related issues, this appear to be distinct from pain. One possible interpretation is that current pain may not be a primary contributor to sleep disruption in gout. Importantly, these findings highlight that simply reinforcing the need for regular, good quality sleep will not be sufficient in this patient group, as the majority have routines which allow for adequate sleep. Instead, it will be important to identify patient-specific sleep complaints and concerns and manage these on a case-by-case basis. Our findings are unique in linking gout with a diverse range of sleep outcomes beyond self reported duration and quality from a patient perspective, which provides important insight into the sleep health messaging and advice likely to benefit patients living with gout. Specifically, patients with gout differ from the general population, with reports of feeling they receive adequate opportunity to sleep. Given the relationship identified between OSA and gout, this patient group are more likely to benefit from messaging about assessment for sleep disorders rather than sleep hygiene (e.g. habitual routines, and allowing adequate opportunities to sleep).

One of the strengths of our study was the large sample that closely matched the general Australian population. It should be noted however, that while the sample was representative in regards to age, gender and geographical location across metropolitan and rural locations, there was a higher proportion of post-school qualifications, particularly Bachelor degrees or higher, than population estimates. We used self-reported doctor diagnosed gout, which has been shown to be reliable in epidemiologic studies [17]. Findings should be interpreted in the context of the study limitations. A key limitation is the cross-sectional nature of our study, so we were unable to comment on causation. An unmeasured shared risk factor for both gout and sleep apnea, is an important consideration, and a source of potential bias in our study. It is important to note that a large case control study using primary care data, published earlier this year, has shown that after adjustment for renal function, recent use of diuretics and heart failure, the association between gout and sleep apnea was no longer seen in males [18]. We were unable to correct for renal function as were limited to information collected via an existing patient questionnaire and did not have specifics related to treatments used.

Our study has highlighted that sleep disorders and gout are common and frequently comorbid in the Australian population. Sleep apnoea and gout are both associated with significant cardiovascular morbidity and mortality, but are also treatable. An awareness of the coexistence of both conditions should lead to increased screening and appropriate treatment tailored to patient needs. Further research is required to delineate the nature of the relationship between conditions, and also to establish if treatment of one condition may influence the trajectory of the other condition.

\section{Abbreviations \\ OSA: Obstructive sleep apnoea; BMI: Body mass index; RLS: Restless legs syndrome; PMLS: Periodic leg movements of sleep}

\section{Acknowledgements}

The authors acknowledge the support of the Australian Sleep Health Foundation in funding this research.

\section{Authors' contributions}

JNT and CLH conceived of the OSA and gout analyses. JNT wrote the manuscript. ACR conducted statistical analyses and contributed to writing the manuscript. SL assisted with statistical analysis. ACR, SA, TG and RA collected the data. All authors contributed to revision and preparation of the manuscript. All authors read and approved the final manuscript.

\section{Funding}

The survey was supported by the Sleep Health Foundation, an Australian non-for profit organization devoted to improving sleep health, with an unrestricted grant awarded to Adams, Appleton, Gill and Reynolds, from Merck Sharp \& Dohme (Australia) Pty Limited, which had no part in the study conception, planning, execution or reporting. 


\section{Availability of data and materials}

The dataset(s) supporting the conclusions of this article is (are) included within the article (and its additional file(s)).

\section{Declarations}

\section{Ethics approval and consent to participate}

Ethical approval was obtained from Human Research Ethics Secretariat of The University of Adelaide Office of Research Ethics, Compliance and Integrity (H-2018-214). Informed consent was provided upon commencement of the study after reading the study information. Research was performed in accordance with the declaration of Helsinki. Participants remained anonymous and there was no risk posed by participation in the survey. Participation was voluntary and participants were free to withdraw at any time.

\section{Consent for publication}

Not applicable.

\section{Competing interests}

The authors declare that they have no competing interests.

\section{Author details}

'Rheumatology Unit, The Queen Elizabeth Hospital, Woodville, SA, Australia. ${ }^{2}$ Flinders Health and Medical Research Institute (Sleep Health)/Adelaide Institute for Sleep Health, College of Medicine and Public Health, Flinders University, Bedford Park, SA, Australia. ${ }^{3}$ Adelaide Medical School, University of Adelaide, Adelaide, SA, Australia.

Received: 11 January 2021 Accepted: 29 April 2021

Published online: 28 August 2021

\section{References}

1. Pisaniello HL, Lester S, Gonzalez-Chica D, Stocks N, Longo M, Sharplin GR, et al. Gout prevalence and predictors of urate-lowering therapy use: results from a population-based study. Arthritis Res Ther. 2018;20:143. https://doi. org/10.1186/s13075-018-1633-9

2. Disveld IJM, Fransen J, Rongen GA, Kienhorst LBE, Zoakman S, Janssens HJEM, et al. Crystal-proven gout and characteristic gout severity factors are associated with cardiovascular disease. J Rheumatol. 2018;45(6):858-63. https://doi.org/10.3899/jrheum.170555.

3. Adams RJ, Appleton SL, Taylor AW, Gill TK, Lang C, McEvoy RD, et al. Sleep health of Australian adults in 2016: results of the 2016 Sleep Health Foundation national survey. Sleep Health. 2017;3(1):35-42. https://doi.org/1 0.1016/j.sleh.2016.11.005

4. Singh JA, Cleveland JD. Gout and the risk of incident obstructive sleep apnea in adults 65 years or older: an observational study. J Clin Sleep Med. 2018;14(09):1521-7. https://doi.org/10.5664/jcsm.7328.

5. Shi T, Min M, Sun C, Cheng C, Zhang Y, Liang M, et al. A meta-analysis of the association between gout, serum uric acid level, and obstructive sleep apnea. Sleep Breath = Schlaf Atmung. 2019;23(4):1047-57. http://doi.org/1 0.1007/s11325-019-01827-1.

6. Mirrakhimov AE, Mirrakhimov EM. Obstructive sleep apnoea, gout and cardiovascular risk: a worth studying association. Med Hypotheses. 2013; 81(4):749.

7. Smolensky MH, Portaluppi F, Manfredini R, Hermida RC, Tiseo R, SackettLundeen LL, et al. Diurnal and twenty-four hour patterning of human diseases: acute and chronic common and uncommon medical conditions. Sleep Med Rev. 2015;21:12-22. https://doi.org/10.1016/j.smrv.2014.06.005.

8. Choi HK, Niu J, Neogi T, Chen CA, Chaisson C, Hunter D, et al. Nocturnal risk of gout attacks. Arthritis Rheumatol. 2015;67(2):555-62. https://doi.org/10.1 002 /art.38917.

9. Appleton SL, Reynolds AC, Gill TK, Melaku YA, Adams R. Waking to use technology at night, and associations with driving and work outcomes: a screenshot of Australian adults. Sleep. 2020;43(8). https://doi.org/10.1093/ sleep/zsaa015.

10. Australian National Health and Medical Research Council. Australian guidelines to reduce health risks from drinking alcohol: commonwealth of Australia; 2009 [Available from: https://www.nhmrc.gov.au/about-us/publica tions/australian-guidelines-reduce-health-risks-drinking-alcohol].
11. Blagojevic-Bucknall M, Mallen C, Muller S, Hayward R, West S, Choi H, et al, The risk of gout among patients with sleep apnea: a matched cohort study. Arthritis Rheumatol. 2019;71(1):154-60. https://doi.org/10.1002/art.40662.

12. Zhang Y, Peloquin CE, Dubreuil M, Roddy E, Lu N, Neogi T, et al. Sleep apnea and the risk of incident gout: a population-based, body mass indexmatched cohort study. Arthritis Rheumatol. 2015;67(12):3298-302. https:// doi.org/10.1002/art.39330.

13. Simpson L, Hillman D, Cooper M, Ward K, Hunter M, Cullen S, et al. High prevalence of undiagnosed obstructive sleep apnoea in the general population and methods for screening for representative controls. Sleep Breath. 2013;17(3):967-73. https://doi.org/10.1007/s11325-012-0785-0.

14. Szatmari JS, Bereczki D, Fornadi K, Kalantar-Zadeh K, Kovesdy CP, Molnar MZ. association of restless legs syndrome with incident Parkinson's disease. Sleep. 2017:40(2):zsw065. https://doi.org/10.1093/sleep/zsw065.

15. Yazar HO, Yazar T, Yildirim T, Keşkek A, Altunkaynak Y. Assessment of serum uric acid levels in patients with restless legs syndrome. Acta Neurol Belg. 2019;119(3):461-6. https://doi.org/10.1007/s13760-019-01177-5.

16. Hillman D, Mitchell S, Streatfeild J, Burns C, Bruck D, Pezzullo L. The economic cost of inadequate sleep. Sleep. 2018;41(8). https://doi.org/10.1 093/sleep/zsy083.

17. McAdams MA, Maynard JW, Baer AN, Köttgen A, Clipp S, Coresh J, et al. Reliability and sensitivity of the self-report of physician-diagnosed gout in the campaign against cancer and heart disease and the atherosclerosis risk in the community cohorts. J Rheumatol. 2011;38(1):135-41. https://doi.org/1 0.3899/jrheum.100418.

18. van Durme C, Spaetgens B, Driessen J, Nielen J, Sastry M, Boonen A, et al. Obstructive sleep apnea and the risk of gout: a population-based casecontrol study. Arthritis Res Ther. 2020;22(1):1-9.

\section{Publisher's Note}

Springer Nature remains neutral with regard to jurisdictional claims in published maps and institutional affiliations.

\section{Ready to submit your research? Choose BMC and benefit from:}

- fast, convenient online submission

- thorough peer review by experienced researchers in your field

- rapid publication on acceptance

- support for research data, including large and complex data types

- gold Open Access which fosters wider collaboration and increased citations

- maximum visibility for your research: over $100 \mathrm{M}$ website views per year

At $\mathrm{BMC}$, research is always in progress.

Learn more biomedcentral.com/submissions 